\title{
Multimodal Interactive Environments for Art Education of Children with Autism Spectrum Disorder
}

\author{
Simona Zalyte-Linkuviene ${ }^{1} \mathrm{MA}$; (D) Vytautas Zalys ${ }^{2} \mathrm{PhD}$ \\ Vilnius Engineering and Technology Lyceum ${ }^{1}$; Siauliai University ${ }^{2}$, Lithuania \\ simona.zalytelin@gmail.com ${ }^{1}$; zalysvytautas@yahoo.com ${ }^{2}$
}

\begin{abstract}
The emerging of digital technology not only encourages the development of new tools but also changes traditional approaches to solving emerging problems. The sound, music, art and colour that prevailed in the 20th century forms of therapy are being replaced by integrated systems that overcome many of these forms thanks to digital technology. With the increasing number of people with autism spectrum disorder (ASD) in the world, such systems provide new opportunities for the educating of such persons. The article presents an interactive tool for the education of children with ASD using audio, video and computer technologies and assesses its potential impact. The aim of this study is to evaluate an interactive instrument developed for the education of children with ASD. The methodology of qualitative research was applied. Following the objectives of ensuring the interactivity of the process, provoking all perceptions of the subject and developing the subject's ability to respond to the environment a personalized audio-visual environment was created. The study was conducted on one subject and a case study method was used. The particularly rapid development of computer technology has transformed a computer from a device consisting of a keyboard and screen into a device that makes all our senses responsive - sound, image, interactivity and real-life simulation. Interactive video projections further highlight the possibilities of combining these media. The opportunity to manage and to participate in such interactions becomes a great opportunity to learn about the world and make personal contact with it, especially for children with ASD.
\end{abstract}

Keywords: interactive audio-visual technologies, autism spectrum disorder, sound, pre-school education.

\section{Introduction}

Despite the better quality of life and medical care, a better understanding of hygiene conditions, there is a steady increase in the number of children with learning difficulties in the world. According to a study by UNICEF (UNICEF, 2013), about $15 \%$ of the Earth's population suffers from various forms of special educational needs (SEN). One of the fastest growing forms of SEN is autism spectrum disorder (ASD) (Ainscow, Dyson, Weiner, 2013). In 2000, one in 150 ASDs in the world was diagnosed within 3-21 years old people and in 2016 one in 88 of them were already counted (Lai, Lombardo, BaronCohen, 2013; Preece, Howley, 2018). This is characterized as a neurological developmental disorder that most affects the development of language, communication, social skills, and behaviour (Powers, 2000; Frith, 2008; O'Connor, 2012; Sokhadze et al., 2016).

One of the essential features of subject's with ASD is a complicated ability to recognize one's own and others' emotional language. This is the basis of empathy and the ability to orientate in the social space which is essential in our lives (Gonsalves, 2010; Santomauro, Sheffield, Sofronoff, 2017). Despite the importance of emotions in social life it has rarely become the object of research in twentieth-century scientific theories and research. The prevailing view was that emotions are secondary and must obey rational thinking (Zajonc, 2000). It is therefore not surprising that there is not much research in this area. The dominant traits that researchers focus on include the relationship of such individuals to: a) the expression of another person and their emotions; b) visual information; c) sound and music; d) audiovisual interactivity and e) identification of all above features in the educational process (Curry, Meyer, McKinney, 2006; Bach, Seifritz, Dolan, 2015; Sokhadze et al., 2016; Nelson, 2012; Stiegler, Davis, 2010; Brockett, Lawton-Shirley, Giencke-Kimball, 2014).

It is argued that the experience and expression of emotions can be learned by communicating through music. However, the emotions evoked by music and life situations have one particularly important difference: in real life emotions always have a very specific reason, and it is quite difficult to say why we experience one or another emotion while listening to music although the mood created by music can 
affect our perception of the world (Jolij, Meurs, 2011). Even more questions arise when analysing the relationship between emotions, music and colour that occurs in the case of synaesthesia.

Predictability of the surrounding world is especially important for children with ASD. And the fact that we respond differently to those sounds for which we are prepared and for which we are not prepared makes it even more difficult to orientate in the environment (Bach, Seifritz, Dolan, 2015). Unpredictability is also increased by different ear sensitivities to audio information (Sokhadze et al., 2016; Jeste, Nelson, 2009). Children experiencing ASD often exhibit a distorted relationship with audio information. Some children with ASD believe that sound can hurt so try to protect the ears by covering them with their hands. Their reaction to sound depends on the context and they may be particularly sensitive to specific sounds but not at all responsive to very loud sound (Nelson, 2012; Stiegler, Davis, 2010; Whitehouse, Bishop, 2008). This interferes with the feeling of fullness of acoustic space (Dunn, Gomes, Gravel, 2008) and has a negative effect on language receptivity (Bomba, Pang, 2004). Problems are solved by exploiting the physical properties of sound. The best-known experiments in this field are the TOMATIS and G. Berard methods (Brockett, Lawton-Shirley, Giencke-Kimball, 2014; Berard, Brockett, 2011). There are differences between these methods but it is basically specially modified audio information designed to stimulate certain areas of the brain. Exposure methodologies are also known that attempt to activate the perception of audio information by combining moments of sound and silence (Voisin et al., 2006).

Vision is in some sense always external to our body (emphasizing the separation between subject and object in perception), sound on the contrary resonates through our body, literally embodying the information that it carries on as we vibrate through the world we are surrounded/placed into. That is, listening pulls you into the world, looking separates you from the world (Valle, 2010). The essential factor determining the ability to understand human actions is the ability to combine into one whole the information obtained by all means of perception. Time (sound and music), space (visual space) and semantically similar information facilitate behaviour and the development of behavioural patterns (Meyer, Greenlee, Wuerger, 2011). This synthesis of video and audio material is especially important when interacting with other people. Emotional facial expressions and observation of lip movements greatly facilitate language comprehension. The expression of the speaker's face during communication increases the comprehension of audible language as much as if the interlocutor spoke 15-20 dB louder (Saito et al., 2005).

The advent of computers and research into their use has shown that they have given children with ASD an additional opportunity to interact with peers. Animated everyday objects displayed on a computer screen help people with ASD to learn to distinguish objects by colour, shape and size, and to develop the ability to associate visible images with sounds (Lányi, Tilinger, 2004). A hugely successful cartoon for children with ASD called Transporters was created in 2008 in USA. Its main characters are trains, cars and tractors with images of faces of actors modelling certain emotions embedded in their front. Actor's simulated emotions have become an excellent learning tool for emotional expression for children experiencing ASD (Golan et al., 2010).

The interactive multimodal environment was chosen as the solution of the above-mentioned problem; therefore, the aim of this study is to evaluate an interactive instrument developed for the education of children with ASD.

\section{Methodology}

A boy was selected for the study who was diagnosed with mixed specific developmental disorders at the Child Development Centre of Lithuania. Experts assessed the boy's condition as moderate disability. Delayed psychological development, a tendency to withdraw from peers, impulsive anger when the agenda is not going according to a pre-arranged plan, especially a brief concentration of attention, a tendency to resist or protest against the emergence of new things in a familiar environment were observed. The boy's language was limited to 3-5-word sentences. The consents of the kindergarten administration and the child's parents to participate in the experiment were obtained.

To evaluate the possibilities of developing the application of interactive audio-visual technologies in working with a child in 2015 (from September to December). An empirical experimental study was carried out and the case analysis methodology was applied. A questionnaire was prepared for the child's 
parents, the analysis of the conclusions of the experts assessing the child's health was performed, and 8 interactive animated projections were prepared. All 16 experimental lessons were filmed.

The questionnaire for parents consisted of 18 open-ended questions. The questionnaire starts with demographic questions. The rest were divided into 4 blocks: I) development of cognitive abilities; II) emotional stability after lessons; III) social initiative; IV) fine motor skills and phonetic abilities. The survey was repeated three times: at the beginning of the research - on September 3, 2015, during the research - on October 29, 2015 and at the end of the study - December 20, 2015.

The conclusions and recommendations of the experts (psychologist, speech therapist, occupational therapist and social workers of the Child Development Centre certified in Lithuania) were analysed.

A multimedia Multisensory Environment methodology (Brooks, 2005) was used to create the experimental research environment, the aim of which was to create an environment in which the visual, auditory, and tactile senses were stimulated. Based on different musical tales (Vicente-Yagüe Jara, Guerrero Ruiz, 2015) eight two types of animated video projections were created. The duration of the projection is about 2 minutes. The first type 4 projections were created based on children's Lithuanian folk songs. They supplement the narrator's text with musical inserts made by various musical instruments. The second type of 4 projections was based on animated images and typical sound examples of various objects that occur in our everyday environment. Animated characters were created using giff technology (Bantjes, 2019), which is characterized by movement. This was done to provoke the movements of the subject. All projections were complemented by various coloured interactive symbols (circles of various sizes, images of flower, blossoms and birds). Covering any symbol on his hand, a sound or musical insert characteristic of one of the projection characters sounded.

To accustom the child to various acoustic and visual environments the projections were demonstrated on a variety of surfaces (walls, floors, doors, using two planes in the corners of the room, etc.). The computer program EyeCon 1.6 and a webcam were used to create the interactivity of the symbols. It made possible to activate the areas of the screen in which the symbols were mentioned. The zones were associated with appropriate audible symbols. Closing a character on the screen by hand activated the screen area for that symbol. In some cases, it was possible to activate several characters at once. In other projections the child was forced to wait for the previously activated symbol to stop sounding and only then could a new one be activated. The faces of the human figures (girl, boy, grandfather) reflected a specific emotional state (joy, sadness, peace, surprise) in harmony with the sounding music. The scheme of creating an interactive environment is presented in Figure 1.

The educational experiment was conducted in a kindergarten, which the boy has been attending since 2015 March. Detailed recommendations

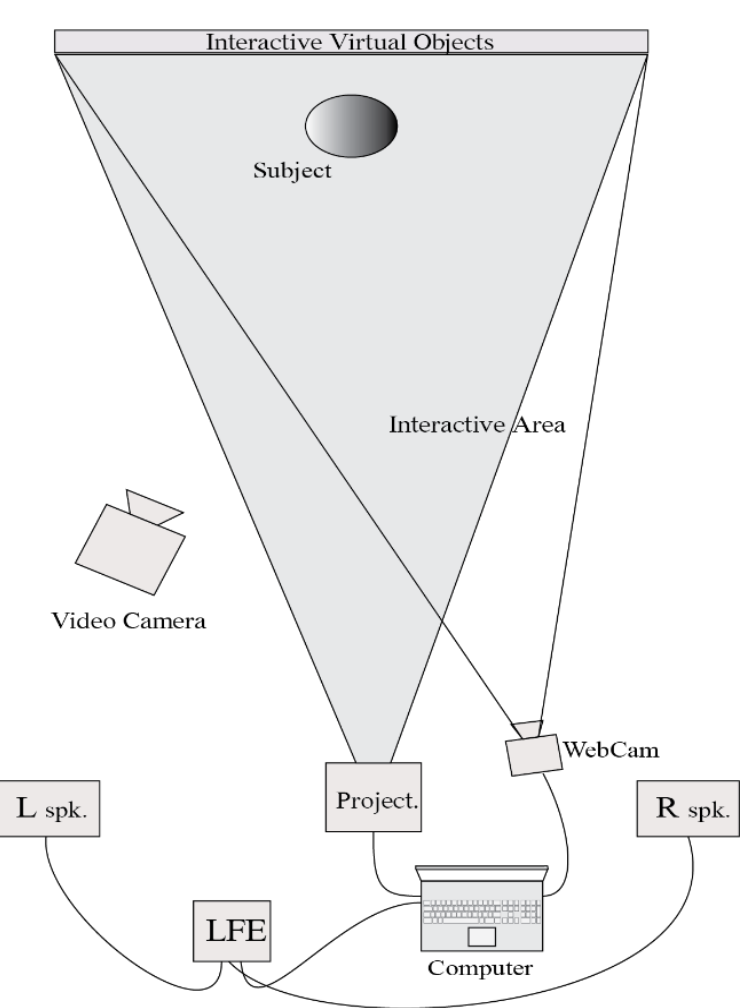

Figure 1. Scheme of creating an interactive environment.

how to organize the experimental activities were prepared. Educational activities were organized twice a week. A total of 16 weeks. The recommendations referred to the emphasis on those places of the projections (by repeating them or otherwise drawing the child's attention) where the projection characters were uttered with specific concepts and different styles of pronunciation. Some of the projections used more than one piece of music to reflect a different mood, therefore the boy was trained to perform music and video selection exercises quickly and accurately. By demonstrating projections on different surfaces 
(especially on the floor) the coordination of the child's movements was developed and the predictability of the sequence of actions was taught. This ability was also taught by giving the child the opportunity to choose for themselves when and what audio or video signal should dominate with the help of interactive symbols. It was taught to feel the importance not only of sound but also of moments when no sounds (i.e., silence) (Voisin et al., 2006).

A model of the activities and measures used in the experiment is presented in Figure 2.

To prepare the child for the projection each lesson begins with a reading of a fairy tale. Gradually the characters are introduced, the main feature of them is described by imitating computer-broadcast music or sounds of nature and by analysing pre-prepared drawings depicting different moods. This creates a musical tale. After reading and partially playing a musical fairy tale we move on to an interactive projection depicting the same fairy tale. During it the characters are re-introduced their control is evaluated, the audio material related to the characters is tested and the movements of the characters are demonstrated. The whole projection occurs at the sound of a tale text entry.

Each element of the projection: the text of the fairy tale being read, the sounds or music associated with the characters, the animation of the characters can be stopped and repeated at any time. Each lesson takes place in a different environment (in another room or part of it), the projection is demonstrated on a different surface (side walls of the room, corners of the room on two walls, on the door and floor).

A questionnaire survey of the parents of the study child was organized three times: at the beginning of the experiment, at the end of the second month, and at the end of the experiment.

\section{Results and Discussion}

To record the course of the experiment as consistently as possible, 16 lessons were filmed (one on each week). This accumulated 320 min. videos (average 20 minutes per lesson). Multimodal transcription methodology (Cowan, 2013) was used for video analysis. 7 most frequently externally monitored behavioural factors and their accounting indicators based on the initial analysis of the video material were identified:

- process verbalization - measured by the number of cases when the subject tries to retell the content of the fairy tale during the projection;

- voluntary attention and demonstration of a sense of rhythm of the process - measured by the number of positive cases; each projection was designed to contain 8 cases in which the subject must demonstrate the ability to maintain attention; this is seen when, at the end of one projection element and the beginning of another the subject tries to wait for the momentary beginning of the new element;

- confidence and desire to combine elements of the projection process - measured in cases where the subject tries to combine visual and audio symbols of different characters;

- copying singing of characters - measured in cases where the subject is trying to sing;

- coordination of movements - the ten-point system evaluates the accuracy of the subject's movements in controlling the projection processes;

- simulation of projection character movements - measured by the number of cases;

- ability to find and associate a character and its characteristic sound symbols - measured by the number of cases. 
Analysis of the factors of video material and their changes during the study are presented in Figures 3-9.

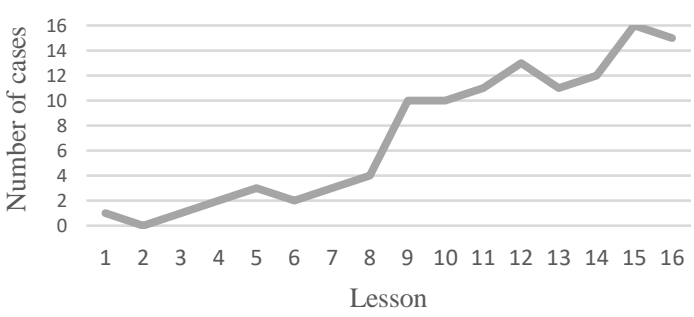

Figure 3. Process verbalization.

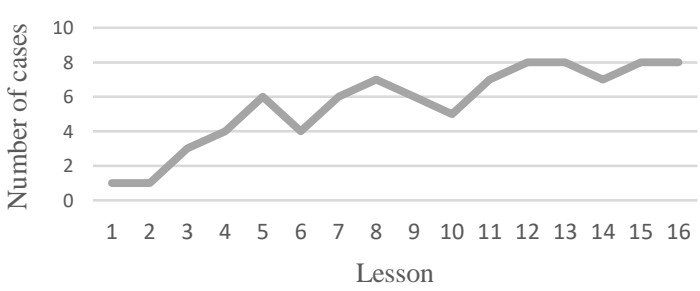

Figure 5. Simulation of projection character movements.

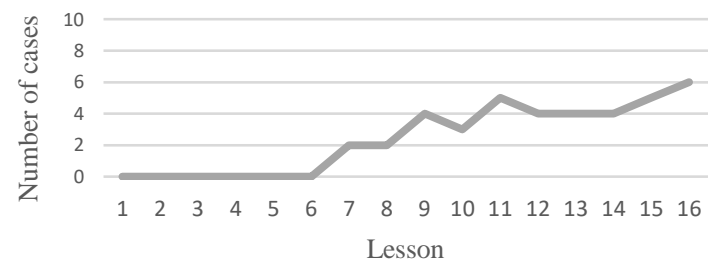

Figure 7. Copying singing of characters.

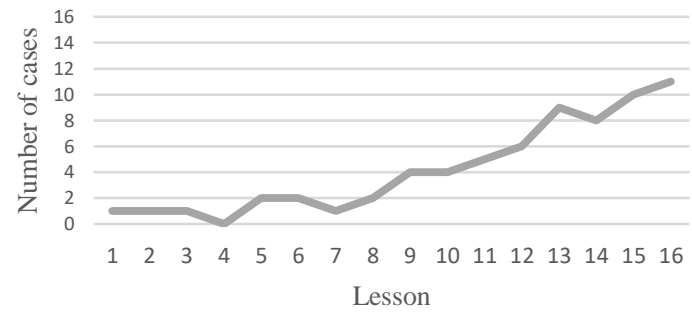

Figure 4. Ability to find a character and associate it with sound symbol.

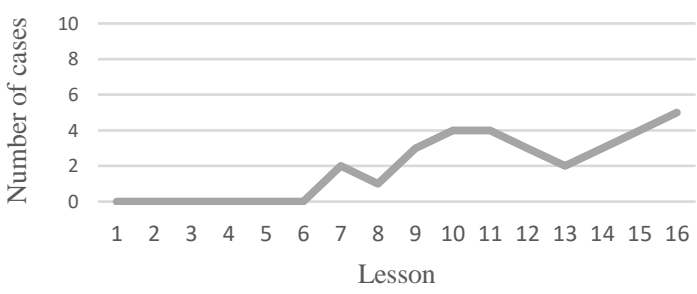

Figure 6. Confidence and desire to combine elements of the projection process.

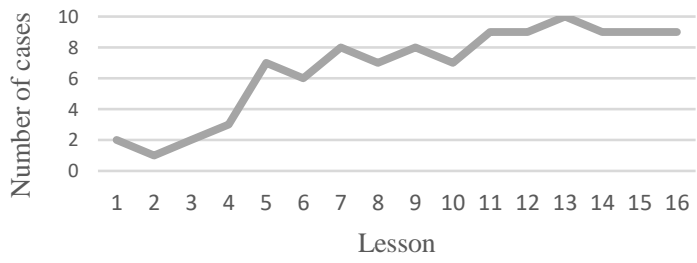

Figure 8. Coordination of movements.

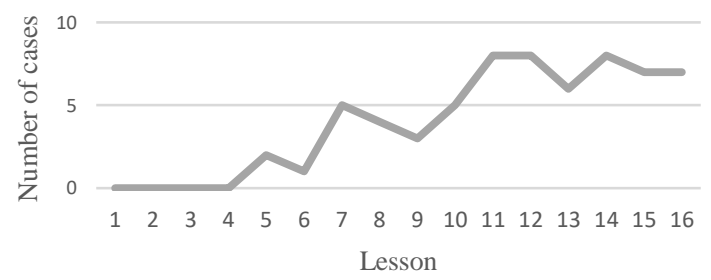

Figure 9. Voluntary attention and demonstration of a sense of rhythm.

The analysis of the videos showed that at the beginning of the study the subject had difficulty connecting to the game. There were frequent cases when he left the playing field trying to engage in other activities. Since the fifth week of the study, the number of such objections has decreased significantly. When participating in a musical fairy tale reading or interactive projection activity, the subject increasingly expressed a desire to re-listen to or review material characterizing some of the characters.

From the eleventh week onwards, there was a desire to combine the elements of the projection not as planned. In this way when the story of "Grandfather" (a fairy tale character) sounds, the researcher additionally activated the chirping of the carriage wheel, tried to combine the sounds of the bird's chirping and running water, activating increasingly characters by stopping and restarting the projection. By doing so the subject showed a desire to relate the content presented in the projection to certain structures and demonstrated the basics of creative abilities.

Based on the results of the questionnaire survey of the subject's parents it can be stated that the change in the child's mood has stabilized in the home environment. Although the pronunciation of some words remained irregular the vocabulary clearly expanded. The ability to engage in the same activity for longer and the desire to achieve a result are observed. There were signs of self-planning. Frequent activities are 
accompanied by restrained singing and movements that demonstrate the rhythmic pulsation of music. There was a significant decrease in the number of particularly pronounced emotional reactions.

Positive developments in the field of fine motor control and expanded active and passive vocabulary were noted after repeated expert assessments by a psychologist occupational therapist and speech therapist. Irregular interdental pronunciation of some sounds remained but phonemic hearing was improved. The ability to tell from a picture or from own experience has changed positively. According to the occupational therapist the desire to perform all tasks well and completely was observed, the concentration of attention improved. Improved fine motor tasks that require eye-hand coordination skills and finger strength. The recognition of objects similar in colour, shape, and size has improved.

Audio-visual technologies in our daily life gives the opportunity to learner to become a process manager, choosing both the direction and the level of complexity. Because in such activities the audio material confirms or denies the correctness of the choice of visual material and the interactivity of the activity pushes the child into a time frame, urging them to take the next action. It is the development of attention and ability to think abstractly. It is very different from activities at home or in a lesson, when the child receives a specific task and his goal is to find one correct answer. Here the possible outcome of the activity is constantly changing depending on the child's choices.

\section{Conclusions}

Audio-visual technology was used in the study in such a way that the experimental environment did not differ significantly from the subject's everyday environment. Although the first steps were quite cautious. The solution to the problems that emerged as the investigation accelerated gained signs of play. At the beginning of the study the experimental process was seen as a phenomenon that must be performed. At the end of the experiment, however, the subject seemed to become part of the game. By trying to combine different visual and aural symbols of different characters he has already demonstrated a desire to create.

The particularly rapid development of computer technology has transformed a computer from a device consisting of a keyboard and screen into a device that makes all our senses responsive - sound, image, interactivity and real-life simulation. Interactive video projections further highlight the possibilities of combining these media. The opportunity to manage and to participate in such interactions becomes a great opportunity to learn about the world and make personal contact with it, especially for children with ASD.

The combination of audio-visual information (audio, video and animation) in video projection is a great opportunity for people with ASD to learn to understand the emotional expression of other people, to develop phonetic hearing and enrich vocabulary. The interactivity of the projections provides an opportunity to develop the coordination of movements.

The experiment did not require particularly large material investments or special training from the researchers and can therefore be easily repeated. Given that similar hardware and software are changing very rapidly it can be expected that the newly performed experiments with interactive projections will reveal the possibilities of educating new individuals with ASD.

\section{Bibliography}

1. Ainscow M., Dyson A., Weiner S. (2013). From exclusion to inclusion. Manchester: Centre for Equity in Education, University of Manchester. Retrieved from https://files.eric.ed.gov/fulltext/ED546818.pdf

2. Bach D.R., Seifritz E., Dolan R.J. (2015). Temporally Unpredictable Sounds Exert a ContextDependent Influence on Evaluation of Unrelated Images. PLoS One, 10(6), e0131065. doi: 10.1371/journal.pone.0131065

3. Bantjes R. (2019). Prie-Cinema, Prie-GIFF, or Auto-Erotic Machine Art? In P. Arantes, V.J. Sá, P.A. da Veiga, A. Fernandes-Marcos (Eds.), The Proceedings of the International Conference on Digital and Interactive Arts (Artech 2019), 9. New York, NY: Association for Computing Machiner, Article No.: 32, 1-8. doi: 10.1145/3359852.3359897

4. Berard G., Brockett S. (2011). Hearing equals behavior: Updated and expanded. Manchester Center, VT: Northshire Press. 
5. Bomba M., Pang E.W. (2004). Cortical auditory evoked potentials in autism: a review. International Journal of Psychophysiology, 53(3), 161-169.doi: 10.1016/j.ijpsycho.2004.04.001

6. Brockett S., Lawton-Shirley N.K., Giencke-Kimball J. (2014). Berard auditory integration training: Behavior changes related to sensory modulation. Autism Insights, 6, 1-10. doi: 10.4137/AUI.S13574

7. Brooks A.L. (2005). Enhanced Gesture Capture in Virtual Interactive Space (VIS). Digital Creativity. 16(1), 43-53. doi: 10.1080/14626260500147769

8. Cowan K. (2013). Multimodal transcription of video: examining interaction in Early Years classrooms. Classroom Discourse, 5(1), 6-21. doi: 10.1080/19463014.2013.859846

9. Curry D.G., Meyer J.E., McKinney J.M. (2006). Seeing versus perceiving. What you see isn't always what you get. Professional Safety, 51(6), 28-34. Retrieved from http://www.as.wvu.edu/psyc101/contents/extra_credit/Ch04ec.pdf

10. Dunn M.A., Gomes H., Gravel, J. (2008). Mismatch Negativity in children with autism and typical development. Journal of Autism Developmental Disorders, 38, 52-71. doi: 10.1007/s10803-007-0359-3

11. Frith U. (2008).Autism: A Very Short Introduction. Oxford: University Press. doi: 10.1093/actrade/9780199207565.001.0001

12. Golan O., Ashwin E., Granader Y., McClintock S., Day K., Leggett V., Baron-Cohen S. (2010). Enhancing emotion recognition in children with autism spectrum conditions: an intervention using animated vehicles with real emotional faces. Journal of Autism and Developmental Disorders, 40, 269-279. doi: 10.1007/s10803-009-0862-9

13. Gonsalves T. (2010). Empathy and Interactivity: Creating Emotionally Empathic Circuits between Audiences and Interactive Arts. In R. Ascott, G. Bast, W. Fiel, M. Jahrmann, R. Schnell (Eds.), New Realities: Being Syncretic. Edition Angewandte. Vienna: Springer, 136-139. doi: 10.1007/978-3-211-78891-2_31

14. Jeste S.S., Nelson C.A. (2009). Event related potentials in the understanding of autism spectrum disorders: An analytical review. Journal of Autism and Developmental Disorders, 39, 495-510. doi: 10.1007/s10803-008-0652-9

15. Jolij J., Meurs M. (2011). Music Alters Visual Perception. PloS One, 6(4), 18861. doi: 10.1371/journal.pone.0018861

16. Lai M-C., Lombardo M.V., Baron-Cohen S. (2013). Autism. The Lancet, 383(9920), 896-910.doi: 10.1016/S0140-6736(13)61539-1

17. Lányi C.S., Tilinger A. (2004). Multimedia and virtual reality in the rehabilitation of autistic children. In K. Miesenberger, J. Klaus, W.L. Zagler, D. Burger (Eds.), Computers Helping People with Special Needs. ICCHP 2004. Lecture Notes in Computer Science, 3118. Berlin, Heidelberg: Springer, 22-28. doi: 10.1007/978-3-540-27817-7_4

18. Meyer G.F., Greenlee M., Wuerger, S. (2011). Interactions between Auditory and Visual Semantic Stimulus Classes: Evidence for Common Processing Networks for Speech and Body Actions. Journal of Cognitive Neuroscience, 23(9), 2291-2308. doi: 10.1162/jocn.2010.21593

19. Nelson C. (2012). Across the Spectrum. Teaching Children with Autism, 51-57.

20. O'Connor K. (2012). Auditory processing in autism spectrum disorder: a review. Neuroscience and Biobehavioral Reviews, 36(2), 836-854. doi: 10.1016/j.neubiorev.2011.11.008

21. Powers M. D. (2000). Children with autism: A parents' guide. Bethesda: Woodbine House.

22. Preece D., Howley M. (2018). An approach to supporting young people with autism spectrum disorder and high anxiety to re-engage with formal education - the impact on young people and their families. International Journal of adolescence and Youth, 23(4), 468-481. doi: 10.1080/02673843.2018.1433695

23. Saito D.N., Yoshimura K., Kochiyama T., Okada T., Honda M., Sadato N. (2005). Cross-modal Binding and Activated Attention Networks during Audiovisual Speech Integration: a Functional MRI Study. Cerebral Cortex, 15(11), 1750-1760. doi: 10.1093/cercor/bhi052

24. Santomauro D., Sheffield J., Sofronoff K. (2017). Investigations into emotion regulation difficulties among adolescents and young adults with autism spectrum disorder: A qualitative study. Journal of intellectual \& developmental disability, 42(3), 275-284. doi: $10.3109 / 13668250.2016 .1236240$ 
25. Sokhadze E.M., Casanoval M.F., Tasman A., Brockett S. (2016). Electrophysiological and Behavioral Outcomes of Berard Auditory Integration Training (AIT) in Children with Autism Spectrum Disorder. Applied Psychophysiology and Biofeedback, 41, 405-420. doi: 10.1007/s10484-016-9343-z

26. Stiegler L.N., Davis R. (2010). Understanding Sound Sensitivity in Individuals with Autism Spectrum Disorders. Focus on Autism and Other Developmental Disabilities, 25(2), 67-75. doi: $10.1177 / 1088357610364530$

27. UNICEF. (2013). Children and Young people with Disabilities. Fact Sheet. Retrieved from https://www.unicef.org/disabilities/files/Factsheet_A5__Web_REVISED(1).pdf

28. Valle A. (2010). Environmental Sound Synthesis, Processing, and Retrieval. Journal on Audio, Speech, and Music Processing, Article ID: 178164, 1-3. Retrieved from https://asmpeurasipjournals.springeropen.com/track/pdf/10.1155/2010/178164.pdf

29. Vicente-Yagüe Jara M.I., Guerrero Ruiz P. (2015). El cuento musical. Análisis de sus components textuales, musicales e ilustrados para el desarrollos de las competencias básicas en Eeducación Primaria [The musical tale. Analysis of its textual, musical and illustrated components for the development of basic competences in Primary Education]. Profesorado: revista de curriculum y formación del profesorado, 19(3), 398-418. Retrieved from https://dialnet.unirioja.es/servlet/articulo?codigo=5361687 (in Spanish)

30. Voisin J., Bidet-Caulet A., Bertrand O., Fonlupt P. (2006). Listening in Silence Activates Auditory Areas: A Functional Magnetic Resonance Imaging Study. The Journal of Neuroscience, 26(1), 273-278. doi: 10.1523/JNEUROSCI.2967-05.2006

31. Whitehouse A.J.O., Bishop D.V.M. (2008). Do children with autism 'switch off' to speech sounds? An investigation using event-related potentials. Developmental Science, 11(4), 516-524. doi: 10.1111/j.1467-7687.2008.00697.x

32. Zajonc R.B. (2000). Feeling and thinking: Closing the debate over the independence of affect. In J.P. Forgas (Eds.), Studies in emotion and social interaction, second series. Feeling and thinking: The role of affect in social cognition. Cambridge University Press, 31-58. 